\title{
Modelling in Urban and Regional Planning: Past, Present, and Yet to Come
}

\author{
P. Rickwood ${ }^{\mathrm{a}}$ \\ ${ }^{a}$ University of Technology, Sydney. PO Box 123 Broadway, NSW 2007. Australia. \\ Email: peter.rickwood@uts.edu.au
}

\begin{abstract}
Modelling in Urban and Regional Planning has an eclectic history - drawing from economics, engineering, geography, physics, and many other fields. These various influences have been a great strength, providing cross-fertilization of ideas and helping to prevent practitioners from getting stuck in methodological or ideological ruts. However, it has also hindered the establishment of a strong shared modelling tradition. Without such a tradition, planners have struggled to create a compelling narrative about how cities evolve and function. Continuing interest in agent-based modelling and complex systems science might result in the creation of such a narrative, but it is not yet coherent enough to compete with the established engineering and economic narratives. Perhaps it is best that it does not compete with them, for they have been, and continue to be, immensely valuable in explaining and testing ideas about cities and how they function. Rather than seeking to create a competing narrative, planners can benefit by engaging with the dominant economic paradigm enough to clearly identify and articulate those areas not already well covered, and then focus research in those areas. Some obvious choices for this concentration of effort include dealing with market-failure and disequilibrium, modelling non-rational behaviour, modelling the role/actions of government, and understanding risk and resilience. Whatever areas we focus on, greater emphasis must be placed on testing and validation of models if they are to be more widely accepted.
\end{abstract}

Keywords: Urban modeling, Urban simulation 


\section{Past and Present}

The birth of what we might loosely term urban modelling began with von Thunen's study of the spatial distribution of production [von Thunen, 1826]. Von Thunen's work was more-or-less contemporaneous with that of David Ricardo, whose work helped establish what has now become the discipline of economics. Von Thunen's work, on the other hand, while followed by important contributions from Weber [1909] and Christaller [1933], did not became anything approaching a discipline. Instead, the spirit of that work lives on today in numerous disparate sub-fields, such as urban economics, urban planning, and urban geography. This rootlessness has had important consequences for urban analysis in general, and mathematical modelling of urban systems in particular.

The first of these consequences is that there is no common tradition of urban modelling - and so no general agreement (except in the vaguest terms) on what essential features an urban model should have, what the standard methods are, or what constitutes theoretical or methodological progress. Economists might agree that a standard land-use model should equilibrate demand/supply for land endogenously through the utility and profit maximizing actions of households, firms, and developers, but plenty of geographers and planners do not accept that markets are a useful way to conceptualize the problem at all.

More troubling even than the difficulty of agreeing on methods is a deeper unresolved epistemological issue. What kind of research is urban modelling? Is it an empirical (positivist) science? Whether yes or no, how should we empirically validate, or falsify, our models? These are not easy questions to answer ${ }^{1}$, given that urban systems are complex and difficult to break into components. Failure to resolve these issues has hampered progress in urban modelling amongst non-economists. Others have recognized the need for epistemological clarity (see, for example, Batty and Torrens [2005]; Manson and O'Sullivan [2006]; Batty [2010]), but too few have rallied in response to these calls, and resolution is nowhere in sight.

Economics, on the other hand, resolved the same issues by pinning its flag firmly to the logical positivist mast ${ }^{2}$. This is not to say economists have all the right answers, or have settled on the 'right' approach, only that within the economic tradition, there is more clarity about what constitutes valid research, and what counts as progress. Such clarity counts for a lot: it has allowed theory and practice to develop without the same questioning, revisitation and reinvention characteristic of urban modelling outside the economic tradition.

For all the reasons outlined above, economists have played an increasingly influential role in urban modelling (theory and practice), mirroring broader growth in influence at the expense of the other social sciences, many of which also equivocated on the issues raised above.

\subsection{The ascension of economic influence}

Within economics, urban analysis has been comparatively neglected, a fact remarked upon by prominent economists (e.g. Krugman [1998]; Mills [2000]). Krugman's explanation for this neglect consists of two key points:

1. Urban activity is fundamentally linked to market imperfection: clustering of activity has benefits (i.e. economies of scale), and this makes perfect competition impossible. While there are have methods for modelling imperfect markets, there aren't many areas where perfect markets are ruled out up-front, and cannot be used even as a simplifying starting-point.

2. Urban activity is "perhaps the most naturally 'non-linear' area in economics" [Krugman, 1998, page 16]. This makes attempts at model-building (and testing) more difficult, and economists attempts at modelling these non-linearities have been "[f]or the most part.... forced and relatively unconvincing" [Krugman, 1998, page 16]. The importance of non-linearity (and positive feedback,

\footnotetext{
${ }^{1}$ These questions have their origin in wider issues raised by the scientific/quantitative revolution in research methods that swept through social sciences in the 1950 s and 1960s. Notably, economics went through the process some half-century earlier.

${ }^{2}$ Some will argue that economists are more accurately described as instrumentalists or confirmationists, and to avoid an endless philosphy-of-science argument, I'm happy to concede on semantics. The salient point here is that economists have made a collective decision and moved on.
} 
complexity, etc) has been more widely acknowledged by non-economists [Harris, 1954; Jacobs, 1961; Wilson, 1981; Batty, 2005].

Despite the relative neglect of urban analysis by economists, the methodological and theoretical consistency provided by a common disciplinary home has meant that economists have, in the last four or five decades, been able to produce the most coherent narrative about how urban systems operate. To better illustrate their increasing influence, let us detour through a quick history of land-use/transport modelling. This history is necessarily short and selective; readers interested in more details should see the excellent summaries in Timmermans [2003]; Wegener [2004].

\subsection{A (very) short history of land-use/transport modelling}

Early work on the Chicago Area Transportation Study drew on theories of city form in urban ecology. Spatial interaction models followed, developed by Lowry [Lowry, 1964], under Hoover (both economists). These models included elements of economic thinking, but few would classify them as economic models - model structure was determined more by data availability and other pragmatic issues than any desire to conform to economic theory.

Work by Alonso [1964] and Mills [1967] in the 1960s established a clearer theoretical basis for urban analysis, but attempts to operationalize these ideas (e.g. Mills [1972]; Hartwick and Hartwick [1974]), were not successful, because the underlying assumptions about behaviour were so unrealistic that the models could not fit real data. So researchers drew inspiration and methods from wherever they could. Some were content to further develop Lowry-style models [Goldner, 1971; Putman, 1983]. Others, such as physicist Wilson, drew on ideas and methods from statistical mechanics [Wilson, 1970] and non-linear dynamics [Wilson, 1981], while Forrester, an engineer interested in system dynamics created models of urban dynamics [Forrester, 1969]. The variety and vitality of competing ideas reflected the diversity and energy of the researchers engaged in the field, which in turn ensured that the field always had sources of inspiration, and did not get stuck in any narrow ideological rut. However, the lack of a disciplinary home, or a large-enough community of practice, has meant that all these disparate efforts have largely stalled ${ }^{3}$, though some of them can be seen as the precursors of contemporary 'complex systems' models (which we will come to shortly).

It was, in the end, methodological developments that heralded in the next generation of models. Daniel McFadden's seminal work on discrete choice McFadden [1974a] was quickly used to model residential location choice Quigley [1976] and travel behaviour [McFadden, 1974b]. This allowed modellers to obtain models that could explain actual behaviour, while still assuming utility-maximization. McFadden's work, coupled with earlier work such as that by Leontief [1966] on linear modelling of inter-sectoral flows, allowed quite detailed treatment of both land-use and transport demand. Both McFadden and Leontief were economists, and these developments helped establish the 'economic approach' as the dominant one. The history of the field from then on has mainly been towards further disaggregation: from sectors to firms, from aggregate groupings of households to households and individuals; with correspondingly increased emphasis of micro-economic fundamentals. Fujita, Krugman, and Venebles' foray into the field [Krugman, 1991; Fujita et al., 2001], while different in character, only serves to underscore the dominance of economic thinking in the area.

This brings us then more or less up to the present, where many view the 'economic approach' as the only valid approach:

[A] fundamental assumption ... is that urban spatial processes play out within markets (for land, floor space, travel, goods and services, etc.), within which the production/consumption (supply/demand) processes interact to determine system outcomes. ... Thus, the ability of a model to capture market demand-supply interactions and to determine market prices endogenously is viewed as an issue of fundamental importance in assessing a given model's capabilities.

\footnotetext{
${ }^{3}$ Lowry-style aggregate spatial interaction models are still used in many metropolitan transport and planning departments, but what progress there is in the development of these models consists primarily of grafting on advances made in more advanced modelling efforts.
} 
Hunt et al. [2005, page 330].

This potted history is only of land-use/transport modelling, which I've chosen to illustrate my point: that the influence of economic thinking and econometric models has grown, to the point where it now dominates. However, the same trend is apparent across the broader field of urban modelling ${ }^{4}$. Complex systems science provides perhaps the last remaining refuge for 'non-economic' modellers, so let us turn our focus there now.

\subsection{Complex systems, cellular automata, and agent based models}

An alternative telling of the history of urban modelling is that in the 70s and 80s, underlying differences in the way researchers understood cities became large enough that a schism developed: researchers dissatisfied with 'reductionist science' approaches either continued to do analytical work within disciplinary homes that did not constrain them to reductionist approaches (geography, urban planning, sociology) or else sought to develop a common alternative approach: a 'complex science' of urban systems.

I will not dwell on the efforts of those working within individual disciplinary homes, but in many of these homes, there is no critical mass of modellers, and so theoretical contributions are small and do not readily disseminate. Stand-alone empirical analyses are still possible (e.g. Peng [1997]; Vandersmissen et al. [2003]; Rickwood and Glazebrook [2009]), but the impact is limited if underlying theory is weak, or not widely shared.

The 'complex systems' approach is one that holds hope for researchers wanting to develop an urban theory that respects the complexity and dynamics of urban systems. Tracing its inspiration back to Jacobs [1961] and Weaver [1948], it emphasizes cities as emergent, far-from-equilibrium systems, more than the sum of their parts, which cannot be usefully analyzed by traditional reductionist approaches. The modelling tools of trade for such systems are cellular automata [Holland, 1975; White and Engelen, 1993] and agent based models (see Portugali [2000]; Benenson [2004]). One of the most consistent and persuasive proponents (and exponents) of this approach to cities has been Michael Batty at CASA [Batty and Xie, 1994; Batty et al., 1999; Batty, 2005], though there have been many others (see Benenson et al. [2002]; Torrens [2003]; Devisch et al. [2005]).

'Cities as complex systems' is the strongest broad-appeal narrative competing with the traditional econoengineering narrative, but it is not yet strong enough to see the establishment of an alternative theoretical and methodological home for urban researchers. Some can see the beginnings of a research community forming:

There is a nascent community of practice emerging at the juncture of computer science, geography, economics, ecology, and urban studies.

Baynes [2009, page 223],

but even advocates of the approach such as Baynes know that it is not yet coherent enough to constitute a 'theory' of urban systems, and there are no signs of it supplanting urban economics as the dominant underlying theory, as many have hoped:

Additionally, [Cellular Automata] offers the opportunity for moving urban modeling away from an overarching allegiance to that old crutch (!), urban economics, and towards an expanded interdisciplinary focus.

Torrens and O'Sullivan [2001, page 166].

\section{THE FUTURE....}

As the saying goes: "It's hard to make predictions - especially about the future", so I will just lay out what I think the key choices are:

\footnotetext{
${ }^{4} \mathrm{And}$, indeed, across urban planning generally, as well as many of the social sciences.

${ }^{5}$ The correct attribution for this quote is unclear: often it is attributed Nils Bohr or Yogi Berra - an unlikely pair if ever there was one!
} 


\subsection{Laissez-faire;}

Continue as we are, with no common literature, heritage, or methodology. Diversity will remain high, but progress more difficult to achieve, or even agree on. A community of practice may develop out of such a loose, diverse, collaborative effort, but I do not think this likely.

\subsection{Engage;}

The choice here is to engage with the economic theory that we have [Alonso, 1964; Mills, 1967; Muth, 1969; Krugman, 1991; Mills, 2000; Fujita et al., 2001; Glaeser, 2008]. This does not mean swallowing economic dogma and all that it implies, but it does mean being familiar enough with the methods and theory to adapt or challenge it directly and empirically. It also means an implicit choice that researchers work within a traditional empirical framework: where theoretical and exploratory research must be supported (or invalidated) by empirical work.

Some researchers have already taken this approach, and are using, challenging, and adapting economic models and ideas. For instance, Timmermans and others in the Netherlands have undertaken empirical work examining non-rational or boundedly-rational decision-making in travel behaviour [Middelkoop et al., 2003; Zhu and Timmermans, 2007; Chorus et al., 2008]. The important point to note about this work is that it does not reject, out of hand, utility-maximizing behavioural models, but instead specifies models which allow for alternatives such as bounded-rationality, and then, crucially, compares the performance of these models against their utility-maximizing counterparts. There has been far too little of this sort of empirical contestation.

The work of Paul Waddell and others on UrbanSim [Waddell, 2000, 2002; Waddell et al., 2003], by using language and methods familiar to economists, is able to draw important lines of distinction. The default residential choice model in UrbanSim, for instance, is a disequilibrium model. This is seen as a deficiency by some economists [Anas, 2007, page 418]. While economists may prefer equilibrium models, it has not been conclusively demonstrated that such models perform better than disequilibrium models. The important point is that by drawing on common models and methods, Waddell sets up the possibility of directly comparing the two approaches: it would be possible, with some work, to directly compare results with the default disequilibrium assumptions against a modified UrbanSim which does ensure market-clearing equilibrium.

Other examples of urban modellers testing the validity of, or variants to, common economic assumptions are: John et al. [1995], who test the appropriateness of Tiebout's residential sorting model [Tiebout, 1956]; de Palma et al. [2007], who look for, and find, capacity constraints in housing choice in Paris; Rosenthal and Strange [2004], and van der Panne [2004], who compare Marshallian and Jacobian explanations for agglomeration economies ${ }^{6}$. I would like to see more empirical research of this sort from urban scholars.

\subsection{Differentiate}

Sensible economists are well aware that their underlying assumptions are unrealistic. Here, for example, is Edwin Mills, one of the fathers of urban economics:

$[\mathrm{N}] \mathrm{o}$ one believes that an entire metropolitan area is in equilibrium.

Mills [2000, page 31].

It is however possible to acknowledge that the underlying assumptions of a model are not true while still viewing that model as a useful metaphor for understanding a more complex reality:

[A]ll our models involve silly assumptions. Given what we know about cognitive psychology, utility maximization is a ludicrous concept; equilibrium pretty foolish outside of financial

\footnotetext{
${ }^{6}$ Incidentally, both conclude that (Marshallian) industry-specific agglomeration economies (labour market pooling, input sharing) are more important than (Jacobian) benefits of diversity.
} 
markets; perfect competition a howler for most industries. The reason for making these assumptions is not that they are reasonable but that they seem to help us produce models that are helpful metaphors for things that we think happen in the real world.

Krugman [1993]

This brings us neatly to the core point of disagreement between those who think that following the traditional empirical scientific approach is still useful, and those who think a new approach is required. Those in the latter group think that the standard approach does not, indeed cannot, produce models that are useful, because the assumptions required force one to deny the very nature of the system being studied. If cities are, as Batty says, the "the examples par excellence of complex systems" [Batty, 2008, page 769], any metaphor that assumes away the fundamental properties of that system cannot be a useful one.

I will not repeat at length the arguments in favour of the development of a 'new kind' of science for the study of cities and other complex phenomena, for others have devoted much time and thought to it (see Wolfram [2002]; Batty [2005]). The argument certainly has intuitive appeal: cities are incredibly complex, with many interacting dynamics and interesting emergent properties. Despite having appeal, the core argument has the worrying corollary that models developed using the 'complex systems' approach are incredibly difficult to empirically validate or falsify:

These models tend to be much richer than their traditional counterparts ... but they are harder to falsify and contain many assumptions and hypotheses that, although plausible, are not testable in any way.

Batty [2010, page 2].

This corollary has served to steer 'complex systems' researchers away from empirical research toward purely theoretical research. But without empirical validation as a means of filtering good models from bad ones, what is the inevitable result? An explosion of exploratory theoretical models, and no satisfying way to agree on what the 'good' models are. The prospects of developing a strong link between theoretical research, empirical research, and practice seem dim, as many practitioners have noted:

[S]ystems of the kind considered here have such volatile behaviour that models representing them may be (more) useful as 'metaphors' or conceptual organizing schemata, than as quantitative planning models.

Couclelis [1989, page 142].

[Complex Systems Science] has strengths in representing and analyzing such features of organized complexity... although its value may be more exploratory rather than predictive.

Baynes [2009, pages 223-4].

The greatest use of such models so far has been by the research community as tools for organising knowledge from empirical studies, and for exploring theoretical aspects of particular systems. ... It is concluded that in terms of decision support, agent-based land-use models are probably more useful as research tools....

Matthews et al. [2007, page 1447].

If this remains the case, and complex urban systems models remain the province only of complex urban systems researchers, this is surely a recipe for irrelevance. If we want these models to be more than theoretical curiosities, then empirical testing and validation is crucial. In many ways, the field would benefit from a moratorium on new model development, with all effort instead directed into finding ways to empirically validate and strengthen the theoretical foundations. Key thinkers recognize the importance of resolving the empirical gap in the field: 
Despite its popularity, research and development in this domain remains in a state of relative stasis, largely constrained by persistent problems in registering simulation scenarios to the real world that model developers seek to simulate.

Torrens [2011, page 335].

\section{The IMPORTANCE OF VALIDATION}

Building models is fun. Or at least most modellers think so, or else they'd've long since moved on to other things. But building models should never be an end in itself - we build models to better understand our world. Or, as von Neumann put it:

The justification of such a mathematical construct is solely and precisely that it is expected to work - that is, correctly to describe phenomena from a reasonably wide area.

von Neumann [1955, page 158].

Validation, in contrast to model-building, is generally not fun. It requires identification of some "natural experiment' which allows a model to be tested, followed by the pain-staking collection of the right data, the fastidious application of one or more well-specified models, and careful interpretation of the results. After all this, the researcher may still be left with inconclusive results that are of no general interest, and are unpublishable.

Regardless of which research paradigm urban researchers choose to work in, an increased emphasis on validation and verification would be beneficial. For those working with traditional models (i.e. taking the 'Engage' option outlined above), it will be convincing empirical research that will make the strongest argument against unrealistic economic assumptions. This area has enormous potential for urban researchers, but to make their cases convincingly they need to both:

- Identify cases of market failure, and situations where standard economic simplifying assumptions are not helpful; and

- Propose alternative assumptions and models that perform better, empirically.

The second step is vital. Pointing out that assumptions are not really true does not mean that those assumptions will be abandoned, nor does it mean that they are not useful in simplifying a model. It is necessary instead to demonstrate that there exist alternate assumptions that do a better job of explaining empirical observations. Or, put another way: even if we accept that models are metaphors (not truth), we need a way of working out which metaphors are more useful. This cannot be done on theoretical grounds alone, but must be tied back to reality in some way.

Researchers taking a non-traditional approach, such as a 'complex systems' approach using agent-based modelling, face a difficult task, for before engaging in empirical validation of their models, they must first develop agreed techniques and methods for conducting such validation. Some groundwork for this has been laid [Wolfram, 1994, 2002], and ways forward suggested some time ago (e.g. Torrens and O'Sullivan [2001, page 168]), but a decade on and progress on this front is still limited.

\section{Conclusion}

Cities are delightfully intriguing, and exasperatingly complex. Given their complexity, and the increasing availability of both computing resources and data (property transactions, disaggregate origin-destination trip data, pedestrian movement, detailed cadastral data, and so on), it seems obvious that modelling and simulation has an important role to play in helping us understand them. This has not, however, been the case - at least in comparison to many other areas of research. Because many of the disciplines that study cities have not had strong quantitative traditions, cities have not received the same modelling and simulation attention that the environmental and natural sciences have. Consequently, economics 
and engineering, which do have strong quantitative traditions, have had the strongest influence on the modelling that has been done. Urban planning, on the other hand, has largely had to import modellers from other disciplines. The same is true to varying degrees of the other disciplines that engage in what is loosely termed 'urban studies'. This has made it difficult to sustain a modelling community of practice. This is something that needs to change for sustained progress to be made, for if we do not speak a common language, we cannot even usefully disagree. And disagreement - resolved through empirical testing - is how research progresses.

In this paper, I've argued that there are some fundamental underlying issues that need resolution. Foremost amongst these is whether, as urban modellers, we are engaging in empirical science; and if so, what kind of 'science' is it, and what burden of evidence is required? Clarity on these questions will make it possible to develop answers to other difficult, but subsidiary questions about model calibration and validation. Personally, I would prefer adoption of a more-or-less traditional scientific approach, with all the distasteful simplifications and limitations that that brings. Others claim that traditional approaches to urban modelling simply do not respect the dynamic nature of cities. This argument clearly has more than a grain of truth in it, but for researchers taking this view, there is an even greater need to demonstrate ways to bridge the 'empirical gap' - the buttressing of theory and models with empirical results.

On this last point, it is important to recognize that validation does not have to include direct validation of the underlying theoretical processes. This is nice, when it is possible, but as Batty points out, much economic theory is not verifiable, and the same is true of other competing theories Batty [2010]. However, while it may be true that some underlying economic theory is unfalsifiable ${ }^{7}$, or just assumed true by convention, this is not the same thing as asserting that models based on these assumptions are themselves untestable. Provided a model makes descriptions or predictions, the usefulness of the model can be tested, and compared against the that of competing models. I would like to see more comparative empirical research of this sort: many of the assumptions made in standard economic models are unrealistic, and often ill-suited to analysis of urban areas where market failure is common. The challenge for urban modellers is to show than a modified, or alternative set of simplifying assumptions work better. There are many promising areas for such investigation: understanding the sources of agglomeration economies; identifying and understanding sources of market failure; testing alternatives to assumptions about market equilibrium, perfect information and rational behaviour; explicitly modelling the role/actions/responses of government ${ }^{8}$; and understanding the adaptive capacity (or resilience) of cities to a range of shocks.

\section{REFERENCES}

Alonso, W. (1964). Location and Land Use. Cambridge, MA: Harvard University Press.

Anas, A. (2007). A regional economy, land use, and transportation model (RELU-TRAN): Formulation, algorithm design, and testing. Journal of Regional Science 47(3), 415-455.

Batty, M. (2005). Cities and Complexity: understanding cities with cellular automata, agent-based models, and fractals. Cambridge, MA: MIT Press.

Batty, M. (2008). The size, scale, and shape of cities. Science 319(5864), 769-771.

Batty, M. (2010). As simple as possible: styles of model, styles of science. Environment and Planning B 37(1), 1-2.

Batty, M. and P. Torrens (2005). Modelling and prediction in a complex world. Futures 37, 745-766.

Batty, M. and Y. Xie (1994). From cells to cities. Environment and Planning B 21.

Batty, M., Y. Xie, and Z. Sun (1999). Modeling urban dynamics through gis-based cellular automata. Computers, environment and urban systems 23(3), 205-233.

Baynes, T. (2009). Complexity in urban development and management. Journal of Industrial Ecology 13(2), 214-227.

\footnotetext{
${ }^{7}$ See, for example, the discussion in Rickwood [2009, page 172-3].

${ }^{8}$ That is, going beyond the common approach of representing government as an essentially passive imposer of regulations and taxes, and instead recognizing the agency of government.
} 
Benenson, I. (2004). Agent-based modeling: From individual residential choice to urban residential dynamics. In M. F. Goodchild and D. G. Janelle (Eds.), Spatially Integrated Social Science, pp. 67-95. Oxford University Press.

Benenson, I., I. Omer, and E. Hatna (2002). Entity-based modeling of urban residential dynamics: the case of yaffo, tel aviv. Environment and Planning B 29(4), 491-512.

Chorus, C., T. Arentze, and H. Timmermans (2008). A random regret-minimization model of travel choice. Transportation Research Part B: Methodological 42(1), 1-18.

Christaller, W. (1933). Central Places in Southern Germany. Jena: Fischer.

Couclelis, H. (1989). Macrostructure and microbehavior in a metropolitan area. Environment and Planning $B$ 16, 141-154.

de Palma, A., N. Picard, and P. Waddell (2007). Discrete choice models with capacity constraints: An empirical analysis of the housing market of the greater Paris region. Journal of Urban Economics 62(2), 204-230.

Devisch, O., T. Arentze, A. Borgers, and H. Timmermans (2005). An agent-based model of residential choice dynamics in non-stationary housing markets. In CUPUM Conference, London.

Forrester, J. W. (1969). Urban dynamics. Cambridge, Mass.: MIT Press.

Fujita, M., P. Krugman, and A. Venables (2001). The Spatial Economy. MIT press.

Glaeser, E. (2008). The Economic Approach to Cities. Harvard Institute of Research Discussion Paper No. 2149.

Goldner, W. (1971). The Lowry model heritage. Journal of the American Institute of Planners 37, 100-110.

Harris, C. D. (1954). The market as a factor in the localization of production. Annals of the Association of American Geographers 44, 315-48.

Hartwick, P. G. and J. M. Hartwick (1974). Efficient resource allocation in a multinucleated city with intermediate goods. Quarterly Journal of Economics 88, 340-352.

Holland, J. (1975). Adaptation in Natural and Artificial Systems. Ann Arbor: University of Michigan press.

Hunt, J. D., D. S. Kriger, and E. J. Miller (2005). Current operational urban land-use-transport modelling frameworks: A review. Transport Reviews 25(3), 329-376.

Jacobs, J. (1961). The death and life of great American cities. Vintage.

John, P., K. Dowding, and S. Biggs (1995). Residential mobility in London: a micro-level test of the behavioural assumptions of the Tiebout model. British Journal of Political Science 25(3), 379-397.

Krugman, P. (1991). Increasing returns and economic geography. Journal of Political Economy 99, 483-99.

Krugman, P. (1993). How I work. The American Economist 37(2), 25-31.

Krugman, P. (1998). What's new about the new economic geography? Oxford Review of Economic Policy 14(2), 7-17.

Leontief, W. (1966). Input-Output Economics. Oxford University Press.

Lowry, I. S. (1964). A Model of Metropolis. RAND Corporation. 
Manson, S. and D. O'Sullivan (2006). Complexity theory in the study of space and place. Environment and Planning A 38(4), 677-692.

Matthews, R. B., N. G. Gilbert, A. Roach, J. G. Polhill, and N. M. Gotts (2007). Agent-based land-use models: a review of applications. Landscape Ecology 22, 1447-1459.

McFadden, D. (1974a). Conditional logit analysis of qualitative choice behavior. In P. Zarembka (Ed.), Frontiers of Econometrics. New York: Academic Press.

McFadden, D. (1974b). The measurement of urban travel demand. Journal of Public Economics 3, 303-328.

Middelkoop, M. V., A. Borgers, and H. Timmermans (2003). Inducing heuristic principles of tourist choice of travel mode: A rule-based approach. Journal of Travel Research 42(1), 75-83.

Mills, E. S. (1967). An aggregative model of resource allocation in a metropolitan area. A.E.R. Papers and Proceedings 57, 197-210.

Mills, E. S. (1972). Markets and efficient resource allocation in urban areas. Swedish Journal of Economics 74(1), 100-113.

Mills, E. S. (2000). A thematic history of urban economic analysis. Brookings-Wharton Papers on Urban Affairs 1, 1-52.

Muth, R. F. (1969). Cities and Housing: The Spatial Pattern of Urban Residential Land Use. Chicago: University of Chicago Press.

Peng, Z. (1997). The jobs-housing balance and urban commuting. Urban Studies 34(8), 1215.

Portugali, J. (2000). Self-organization and the City. Springer Verlag.

Putman, S. H. (1983). Integrated Urban Models. London: Pion.

Quigley, J. M. (1976). Housing demand in the short run: An analysis of polytomous choice. Explorations in Economic Research 3(1), 76-102.

Rickwood, P. (2009). The Impact of Physical Planning Policy on Household Energy Use and Greenhouse Emissions. Broadway, Sydney: University of Technology, Sydney.

Rickwood, P. and G. Glazebrook (2009). Urban structure and commuting in Australian cities. Urban Policy and Research 27(2), 171-188.

Rosenthal, S. and W. Strange (2004). Evidence on the nature and sources of agglomeration economies. Handbook of regional and urban economics 4, 2119-2171.

Tiebout, C. (1956). A pure theory of local expenditures. The journal of political economy, 416-424.

Timmermans, H. (2003). The saga of integrated land use-transport modeling: How many more dreams before we wake up? 10th International Conference on Travel Behaviour Research, Lucerne.

Torrens, P. (2003). Automata-based models of urban systems. Redlands, CA: ESRI Press.

Torrens, P. M. (2011). Calibrating and validating cellular automata models of urbanization. In X. Yang (Ed.), Urban Remote Sensing: Monitoring, Synthesis and Modeling in the Urban Environment, pp. 335-345. Chichester: John Wiley and Sons.

Torrens, P. M. and D. O'Sullivan (2001). Cellular automata and urban simulation: where do we go from here? Environment and Planning B 28(2), 163-168.

van der Panne, G. (2004). Agglomeration externalities: Marshall versus Jacobs. Journal of Evolutionary Economics 14, 593-604. 
Vandersmissen, M., P. Villeneuve, and M. Thériault (2003). Analyzing changes in urban form and commuting time. The Professional Geographer 55(4), 446-463.

von Neumann, J. (1955). Method in the physical sciences. In L. Leary (Ed.), The Unity of Knowledge.

von Thunen, J. H. (1826). The Isolated State. Oxford: Pergammon Press (English Edition 1966).

Waddell, P. (2000). A behavioral simulation model for metropolitan policy analysis and planning: residential location and housing market components of UrbanSim. Environment and Planning B: Planning and Design 27(2), 247-263.

Waddell, P. (2002). UrbanSim: Modeling urban development for land use, transportation and environmental planning. Journal of the American Planning Association 68(3), 297-314.

Waddell, P., A. Borning, M. Noth, N. Freier, M. Becke, and G. Ulfarsson (2003). Microsimulation of urban development and location choices: Design and implementation of UrbanSim. Networks and Spatial Economics 3(1), 43-67.

Weaver, W. (1948). Science and complexity. American Scientist 36(4), 536-544.

Weber, A. (1909). Theory of the Location of Industries. Chicago, IL: University of Chicago Press.

Wegener, M. (2004). Overview of land use transport models. Handbook of transport geography and spatial systems 5, 127-146.

White, R. and G. Engelen (1993). Cellular automata and fractal urban form: a cellular modelling approach to the evolution of urban land-use patterns. Environment and Planning A 25, 1175-1175.

Wilson, A. (1970). Entropy in urban and regional modelling. London: Pion.

Wilson, A. (1981). Catastrophe theory and bifurcation: applications to urban and regional systems. Univ of California Press.

Wolfram, S. (1994). Cellular Automata and Complexity. Reading, MA: Addison-Wesley.

Wolfram, S. (2002). A New Kind of Science. Champaign, IL: Wolfram Media, Inc.

Zhu, W. and H. Timmermans (2007). Approach to incorporating principles of bounded rationality into models of individual decision making. In Proceedings RARSS Conference, San Francisco. 